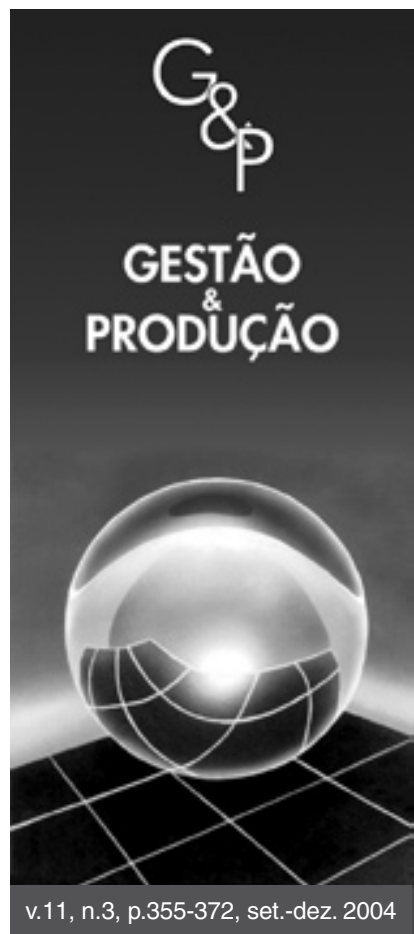

\title{
COORDENAÇÃO DA QUALIDADE EM CADEIAS DE PRODUÇÃO: ESTRUTURA E MÉTODO PARA CADEIAS AGROALIMENTARES
}

\author{
José Carlos de Toledo \\ Miguel Angel Aires Borrás \\ Andréa Rossi Scalco \\ Luciano Silva Lima \\ Grupo de Estudo e Pesquisa em Qualidade (GEPEQ) \\ Departamento de Engenharia de Produção, \\ Universidade Federal de São Carlos, \\ C.P. 676, CEP 13565-905, São Carlos, SP, \\ e-mail: toledo@ @ower.ufscar.br; maborras@dep.ufscar.br; \\ rossiscalco@yahoo.com.br; luciano@dep.ufscar.br
}

Recebido em 26/5/2004

Aprovado em 22/11/2004

Resumo

As empresas de modo geral vivem uma realidade na qual não podem mais planejar nem agir de maneira isolada, exigindo-se um comportamento coordenado entre as que pertencem a uma mesma cadeia de produção. Nesse contexto, a coordenação em cadeias de produção ganha notoriedade por promover o gerenciamento integrado de empresas que compartilham o objetivo de agregar valor ao produto final da cadeia. São vários os motivos que levam à coordenação em cadeias de produção, destacando-se a melhoria da qualidade do produto, bem como a redução das perdas e dos custos de produção e de transação. Este trabalho aborda a problemática da coordenação da qualidade em cadeias de produção agroalimentares. O objetivo é apresentar um modelo de coordenação da qualidade, para auxiliar tanto o processo de garantia da qualidade do produto como o de melhoria da qualidade em toda a cadeia. A estrutura de coordenação da qualidade considera os elementos: a cadeia de produção e seus segmentos, os requisitos de qualidade e de gestão da qualidade dos clientes e do ambiente institucional, o agente coordenador e o sistema de informações para a coordenação. Esse sistema abrange informações referentes a: requisitos da qualidade do produto e da gestão da qualidade; indicadores de desempenho em qualidade da cadeia; e identificação de problemas, planos de ações e acompanhamento de melhorias. O trabalho também apresenta uma ilustração do modelo junto a uma cadeia genérica de produção do queijo minas frescal, com a finalidade de facilitar a sua compreensão.

Palavras-chave: coordenação da qualidade, cadeia de produção agroalimentar, método para coordenação da qualidade.

\section{Introdução}

A crescente preocupação com a segurança e qualidade dos alimentos, como um dos principais fatores competitivos das cadeias de produção agroalimentares (CPA), exige que estas busquem mecanismos para melhoria da gestão da qualidade. De um lado, para dar evidência à qualidade de seus produtos, garantindo que possuam as qualidades intrínsecas esperadas pelo consumidor e incrementando a qualidade percebida. De outro lado, melhorando a qualidade de conformação, buscando reduzir custos de falhas e de perdas.

Essa busca se mostra essencial, haja vista a mudança no comportamento do consumidor, que tende a ser cada dia mais exigente e melhor informado em relação aos produtos que consome, assumindo um importante papel de fiscalizador da qualidade e da segurança, principalmente frente aos casos registrados, em diversos países, de doenças e mortes decorrentes da ingestão de alimentos contaminados, conforme listados por Early (1995).

Observa-se, portanto, que qualidade e coordenação estão na ordem do dia no setor agroalimentar, com as empresas vivenciando as questões da coordenação e da qualidade como elementos-chave para sua sobrevivência e desenvolvimento.

Novas estruturas de governança estão surgindo, especialmente pela necessidade de se coordenar e monitorar as informações sobre a qualidade que passa a ser decisiva 
para se diferenciar, frente às crescentes exigências dos consumidores, varejistas e órgãos de regulação.

A coordenação de CPAs e o estabelecimento de redes de confiança tornam-se uma oportunidade estratégica, para que as empresas consigam coordenar suas cadeias de suprimentos ou se inserir em cadeias de produção coordenadas.

Tanto a qualidade do produto final quanto a própria eficiência da CPA, em termos de desperdícios e de custos com perdas, dependem de ações e práticas de cada um de seus segmentos e das transações de bens, serviços e informações de forma coordenada na cadeia. De modo geral, o fato de cada segmento tradicionalmente administrar seu negócio de maneira individualizada mostrase prejudicial à competitividade da cadeia, o que faz da integração e colaboração entre os segmentos um fator primordial para o sucesso.

Nesse contexto, evidencia-se a importância de gerenciar a qualidade de maneira coordenada ao longo das CPAs, com a expectativa de que, dentre outros benefícios potenciais, essas consigam se ajustar e responder de forma eficiente e rápida às variações das condições do mercado e do ambiente institucional. Os instrumentos tradicionais de gestão da qualidade se limitam a ações no âmbito de empresas. Para tanto, há a necessidade do desenvolvimento de métodos e ferramentas de apoio a essa coordenação na cadeia, ou seja, de instrumentos que criem capacitações e habilidades que permitam às empresas da cadeia receber, processar, difundir e utilizar informações de modo a definir e viabilizar as estratégias da qualidade.

O objetivo deste artigo é apresentar um modelo, constituído por uma estrutura e um método para coordenação da qualidade em CPAs, que auxilie os processos de garantia e de melhoria da qualidade, em todos os segmentos da cadeia de produção.

Ainda que se reconheça a influência das características das transações e dos agentes no processo de coordenação de uma cadeia produtiva, a consideração de tais aspectos encontra-se fora do escopo deste artigo, o qual limita-se a uma proposta para incremento da competitividade das cadeias de produção, por meio da coordenação das práticas de gestão e de melhoria da qualidade realizadas por seus agentes.

Para que se compreenda o que vem a ser coordenação da qualidade em CPAs, faz-se necessário entender alguns conceitos básicos, tais como "cadeia de produção" e "coordenação de cadeias de produção". Em seguida o artigo apresenta o conceito de coordenação da qualidade, a estrutura e o método proposto para essa coordenação, discute as condições para aplicação e as funções do agente coordenador. Apresenta também uma breve ilustração da estrutura e do método proposto.

Tendo em vista as especificidades do modelo, a realização de um teste prático para sua validação é inviável a curto prazo, pelo tempo que seria necessário para sua implantação e coleta de resultados junto a uma cadeia produtiva.

\section{Coordenação de cadeias de produção e fatores de influência}

A cadeia de produção é aqui entendida como uma cadeia de suprimentos simplificada. Enquanto a cadeia de produção é definida como um conjunto de transações seqüenciais e verticalmente organizadas, representando etapas sucessivas de criação de valor, abarcando somente as atividades envolvidas no processo de fabricação do produto, a cadeia de suprimento abarca, além das atividades envolvidas no processo de fabricação, as atividades relacionadas à logística entre as unidades produtivas (Assumpção, 2002).

Essa definição de cadeia de produção relaciona-se diretamente com o conceito de integração de Bechtel e Jayaran (1997), em que a ênfase é dada na integração entre os membros da cadeia, objetivando adicionar valor ao produto, com ênfase no papel do consumidor final na tomada de decisões.

O problema da cooperação entre os segmentos das cadeias produtivas foi apontado por Williamson (1985) como um elemento-chave para a competitividade das empresas, a qual depende da articulação de um conjunto de estratégias empresariais e da cadeia, na busca da adequação de seus recursos produtivos e sistemas de gestão aos padrões de qualidade da concorrência ou na busca da redefinição desses padrões.

A coordenação de cadeias de produção pode ser vista como o gerenciamento integrado de um conjunto de redes de empresas interdependentes, que atuam juntas para agregar valor ao produto final. Ou seja, envolve o gerenciamento dos fluxos de produtos, financeiro, de comunicação, de informação e outros, que transitam do setor de insumos ao setor de consumo final e vice-versa. A coordenação da cadeia de produção pressupõe que as empresas devam definir suas estratégias competitivas e funcionais a partir de seus posicionamentos (tanto enquanto fornecedores como enquanto clientes) dentro das cadeias produtivas nas quais se inserem, estando alinhadas às estratégias da cadeia.

Segundo Boehlje et al. (1998), a motivação para coordenação de cadeias, a fim de ganhar vantagem competitiva, se dá em três fases seqüenciais:

1. Melhoria na eficiência e redução de custos;

2. Redução de riscos quanto à qualidade, quantidade e segurança do alimento; e

3. Satisfação das necessidades dos consumidores.

De acordo com Ziggers e Trienekens (1999), além das pressões do ambiente competitivo, os motivos que tam- 
bém incentivam uma cadeia de produção à coordenação são:

a) perecibilidade dos produtos;

b) variabilidade da qualidade e da quantidade dos insumos fornecidos pelo setor agropecuário, causada por variação biológica, sazonalidade, imprevisibilidade de clima e outros riscos biológicos;

c) diferenças de tempo de produção entre os diversos setores (ou estágios) de produção numa cadeia;

d) complementaridade de insumos agropecuários, principalmente quando são vendidos apenas em "pacotes" de produtos combinados;

e) estabilização de consumo de muitos produtos alimentícios;

f) aumento da exigência do consumidor, quanto ao produto e ao seu método de produção;

g) deterioração da qualidade intrínseca (fator fundamental da qualidade de produtos alimentícios, especialmente dos produtos frescos); e

h) necessidade de capital.

Com base nesses fatores, pode-se dizer que a coordenação de uma CPA pode ser realizada objetivando o controle de forma eficiente das quantidades produzidas, dos custos, dos prazos de produção e de distribuição dos produtos no mercado, e da qualidade do produto, assegurando maior competitividade à cadeia.

Para a maioria das empresas hoje, não é suficiente apenas otimizar as estruturas e infra-estruturas internas baseadas em estratégias de negócios. A grande parte das empresas bem sucedidas são aquelas que têm cuidadosamente estabelecido ligações entre seus processos internos, fornecedores e clientes, considerando uma única cadeia de suprimentos.

Frohlich e Westbrook (2001) constataram que quanto maior o grau de integração da cadeia de produção, melhores serão seus índices de desempenho.

\section{Coordenação da qualidade em cadeias de produção}

Para promover a garantia e melhoria da qualidade ao longo de uma cadeia de produção agroalimentar, é preciso estabelecer um enfoque coordenado (envolvendo produtores, processadores, governo, varejo, exportadores) orientando-se para o mercado, buscando satisfazer suas exigências.

Para a gestão da qualidade na cadeia de produção, um fator fundamental é a aplicação de um sistema de informações, o qual, conforme Schiefer (2002), diz respeito ao fluxo de informações sobre as características de produção, as características da qualidade, o controle de produto e de processos e sobre o suporte a atividades de melhoria da qualidade. Segundo Schiefer (2002), existem duas abordagens para o fluxo de informações dentro da cadeia: a centralizada e a descentralizada (Figura 1).

A abordagem centralizada ocorre quando o fluxo de informações e as regras de comunicação são coordenados por meio de uma instituição central, que atua junto à cadeia de produção. Pode-se citar, como exemplos típicos dessa abordagem, as cadeias de suprimento agroalimentares estritamente controladas da Holanda. O fluxo de informações poderia também ser gerenciado por algum dos segmentos da cadeia, o que é comum em setores com grandes diferenças de poder de mercado (poder de barganha) entre as empresas na cadeia.

Já a abordagem descentralizada é aquela em que o fluxo de informações pauta-se em consensos estabelecidos entre as empresas individuais. Exemplo dessa abordagem seria o caso da cadeia da carne na Dinamarca, cuja coordenação envolve elementos de abordagens gerenciais do Total Quality Management (TQM), integrados com um sistema sofisticado de grupos de discussão em diferentes níveis de gerenciamento na cadeia.

Ainda de acordo com Schiefer (2002), a melhoria no processo de coordenação da cadeia de produção envolve dois níveis de intensidade:

a) um em que as empresas individuais recebem orientação para as melhorias potenciais dos processos, ou de fases destes, internos à empresa, orientadas para os objetivos da cadeia; e

b) outro que considera as características dos processos e das atividades de tomada de decisões em relação a uma estrutura organizacional considerada ótima para a cadeia, sendo que tais estruturas ótimas podem resultar da união de esforços planejados de todos os participantes da cadeia (abordagem centralizada) ou do processo de adaptação entre empresas dependentes mutuamente, com autoridade de decisão própria (abordagem descentralizada).

Coordenar a qualidade em uma cadeia de produção implica em fornecer e receber, dos segmentos da cadeia, informações referentes aos requisitos exigidos da qualidade do produto e da gestão da qualidade e ao grau de

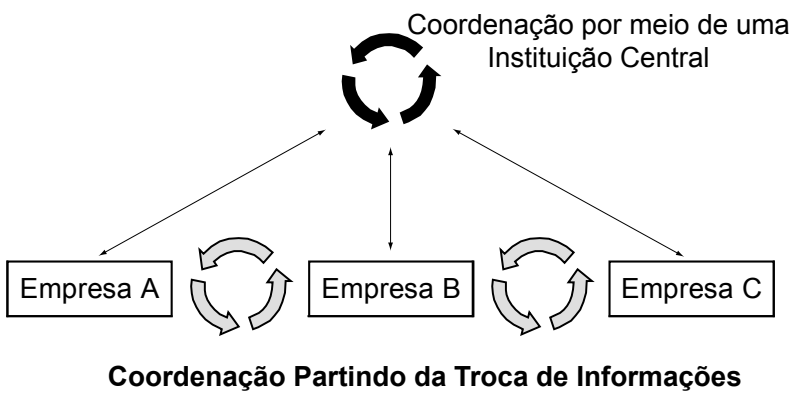

Figura 1. Abordagens para a coordenação da cadeia de Produção Agroalimentar. Fonte: Schiefer (2002). 
atendimento destes, tanto por parte de cada segmento, como por toda a cadeia. Essa transação de informações deve ocorrer por intermédio de um agente coordenador.

A cadeia de produção pode atingir um grau mais elevado de competitividade com a coordenação da qualidade ao longo de suas operações. Todos os segmentos da CPA devem buscar satisfazer, de forma integrada, os requisitos da qualidade do produto - sejam relativos aos atributos intrínsecos ao produto (como por exemplo, valor nutricional e isenção de toxinas), como aos atributos relacionados aos meios de produção (como por exemplo, não utilização de mão-de-obra infantil e preservação do meio ambiente) - e os requisitos de gestão da qualidade (por exemplo: inspeções, controles de processos, identificação e rastreabilidade).

Desse modo, define-se coordenação da qualidade em cadeias de produção como o conjunto de atividades planejadas e controladas por um agente coordenador, tendo por finalidade aprimorar a gestão da qualidade e auxiliar no processo de garantia da qualidade dos produtos ao longo da cadeia, por meio de um processo de transação das informações, contribuindo para a melhoria da satisfação dos clientes e para a redução dos custos e das perdas, em todas as etapas da cadeia de produção. Definindo cada termo chave que aparece no conceito acima apresentado, tem-se:

a)Planejar, controlar e aprimorar a qualidade: tem o sentido dos conceitos da Trilogia da Qualidade de Juran (1990), em que planejamento da qualidade consiste em planejar atividades com o objetivo de criar um processo capaz de gerar produtos que satisfaçam os consumidores; controle da qualidade consiste em controlar processos com o objetivo de avaliar o desempenho real da qualidade e agir, caso haja um desvio; e o aprimoramento da qualidade tem como objetivo melhorar a qualidade dos produtos e processos;

b)Processo de transação das informações: pode ser definido como a aquisição, gestão e distribuição das informações em toda a cadeia de produção. Especificamente para coordenar a qualidade, as informações transacionadas dizem respeito aos requisitos de qualidade do produto e da gestão da qualidade e ao desempenho em qualidade da cadeia de produção; e

c) Agente coordenador: o agente coordenador tem a finalidade de fazer com que as informações relacionadas à qualidade de produto e à gestão da qualidade sejam identificadas, transmitidas e controladas ao longo da cadeia. O agente coordenador cumpre o papel de buscar o consenso em relação às características da qualidade a serem coordenadas e ao foco das ações de melhoria.

As formas de governança são construídas com o objetivo de incentivar e controlar os agentes que atuam nas CPAs. Entretanto, além de uma estrutura de governança adequada, é de fundamental importância que o agente coordenador disponha de um método que o auxilie na tarefa de gerenciamento da qualidade ao longo da cadeia.

Existem vários sistemas e ferramentas com abordagens para a gestão da qualidade focada no âmbito da empresa, como por exemplo, a ISO 9000, o APPCC e as Boas Práticas de Higiene e de Manufatura. Porém, é rara, senão inexistente, a disponibilidade de um método que sintetize e unifique informações para gerenciamento da qualidade, aplicado além das fronteiras das empresas, ou seja, expandindo-se para toda a cadeia de produção, e que integre informações sobre qualidade do produto e gestão da qualidade nos seus diversos segmentos.

Baines e Davies (1998) e Ziggers e Trienekens (1999) listaram alguns dos resultados que podem ser alcançados com a garantia da qualidade numa CPA:

a) aumento da probabilidade de fornecer produtos de qualidade por monitoramento, ação corretiva e melhoria contínua;

b) habilidade de responder e controlar situações de emergência;

c) habilidade para responder a requisitos de órgãos públi cos e de consumidores;

d) aumento da confiança do consumidor com relação a toda cadeia;

e) adição de valor ao produto; e

f) redução de custos totais da produção nos segmentos da cadeia.

A coordenação da qualidade em CPAs pode ser obtida pelo desenvolvimento e aplicação de práticas que podem ser adotadas por uma empresa a montante (sentido cliente-fornecedor) e a jusante (sentido fornecedor-cliente) da cadeia de produção. O Quadro 1 elenca algumas práticas de coordenação da qualidade, praticadas a montante e a jusante na cadeia.

As práticas adotadas devem estar alinhadas com as estratégias competitivas e com as prioridades dos agentes e da cadeia de produção na qual estão inseridas, além de requererem a existência de uma infra-estrutura adequada, de integração e de tecnologia de informação, bem como o compartilhamento de objetivos gerais da CPA.

\section{Estrutura para coordenação da quali- dade em cadeias de produção agroali- mentar}

A Estrutura para Coordenação da Qualidade (ECQ) aqui proposta, inicialmente discutida em Toledo et al. (2003) e Borrás e Toledo (2003), tem como objetivo principal incrementar a competitividade da cadeia de produção, melhorando a satisfação dos clientes e reduzindo as perdas e os custos de produção, por meio da melhoria e 
Quadro 1. Práticas de coordenação da qualidade ao longo da cadeia de produção.

Práticas de Coordenação da Qualidade no sentido Cliente-Fornecedor (a montante)

- Relações de parceria entre a indústria e seus fornecedores, para garantia da qualidade na cadeia;

- incentivos e ações fornecidas pela indústria para melhorar a Qualidade dos produtos recebidos dos fornecedores tais como: investimentos em treinamento, assistência técnica, ações conjuntas de melhoria, pagamento por qualidade, financiamentos de recursos de produção, etc;

- envolvimento do fornecedor no processo de desenvolvimento de novos produtos;

- adoção compartilhada de sistemáticas de gestão da qualidade para garantir a consistência na padronização dos produtos;

- diagnóstico conjunto da qualidade (auditorias da qualidade realizadas no fornecedor);

- elaboração conjunta de planos de ações de melhorias;

- acompanhamento das melhorias implantadas; e

- medição e análise de indicadores de desempenho em qualidade (redução de custos de falhas e de refugos, melhoria na qualidade do produto e na satisfação dos clientes, etc.).

\section{Práticas de Coordenação da Qualidade no sentido Fornecedor-Cliente (a jusante)}

- ações de exigências e orientações para preservação da qualidade do produto final, tais como treinamentos, visando assegurar a forma adequada de manuseio, armazenagem, transporte e exposição do produto final;

- incentivos fornecidos pela indústria para o distribuidor em termos de desconto nos preços, melhores prazos de pagamento, tratamento preferencial, etc., em função da preservação da qualidade do produto;

- obtenção de feedback de informações dos clientes com relação à qualidade do produto e dos serviços oferecidos;

- premiação por serviços prestados pelo distribuidor;

- levantamento e formulação das necessidades específicas dos clientes;

- envolvimento do cliente no processo de desenvolvimento de novos produtos;

- adoção compartilhada de práticas de gestão da qualidade para garantir a consistência na padronização dos produtos;

- diagnóstico conjunto da qualidade (auditorias realizadas nos distribuidores e varejistas);

- elaboração conjunta de planos de ações de melhorias;

- acompanhamento das melhorias realizadas; e

- medição das melhorias por meio de indicadores de desempenho (sobre preservação da qualidade, perdas, satisfação dos clientes, etc.).

garantia da qualidade de seus produtos, de seus respectivos processos de produção e da gestão praticada pelos agentes de cada segmento da CPA.

Desse modo, seriam funções básicas da ECQ:

a) identificar e desdobrar os requisitos da qualidade do produto, para satisfazer a qualidade demandada pelo mercado; e

b) definir, implementar e controlar processos de melhoria da qualidade do produto e de gestão da qualidade.

A ECQ fundamenta-se em quatro elementos básicos (Figura 2):

a) a CPA, seus segmentos e agentes;

b) os requisitos da qualidade do produto e da gestão da qualidade;

c) o Método de Coordenação da Qualidade; e

d) o agente coordenador.

\subsection{Requisitos da qualidade do produto $e$ da gestão da qualidade}

Atender aos requisitos da qualidade do produto e da gestão da qualidade é uma das responsabilidades de cada agente de uma CPA, principalmente aquelas fortemente influenciadas pelo mercado. $\mathrm{O}$ não atendimento a tais requisitos pode resultar na perda de competitividade da cadeia, uma vez que o seu produto não estaria atendendo da melhor maneira possível o que é exigido pelo mercado, incentivando-o a procurar produtos de outra CPA. Garantir que os requisitos sejam atendidos é o principal objetivo da ECQ, sendo que eles podem ser classificados em: Requisitos da Qualidade do Produto (RQP) e Requisitos de Gestão da Qualidade (RGQ).

Os RQP podem ser traduzidos como sendo o conjunto de requisitos válidos para o produto, ou seja, padrões de qualidade do produto que, ao serem atendidos, seriam capazes de satisfazer ao máximo as necessidades e expectativas dos agentes e do consumidor final. 


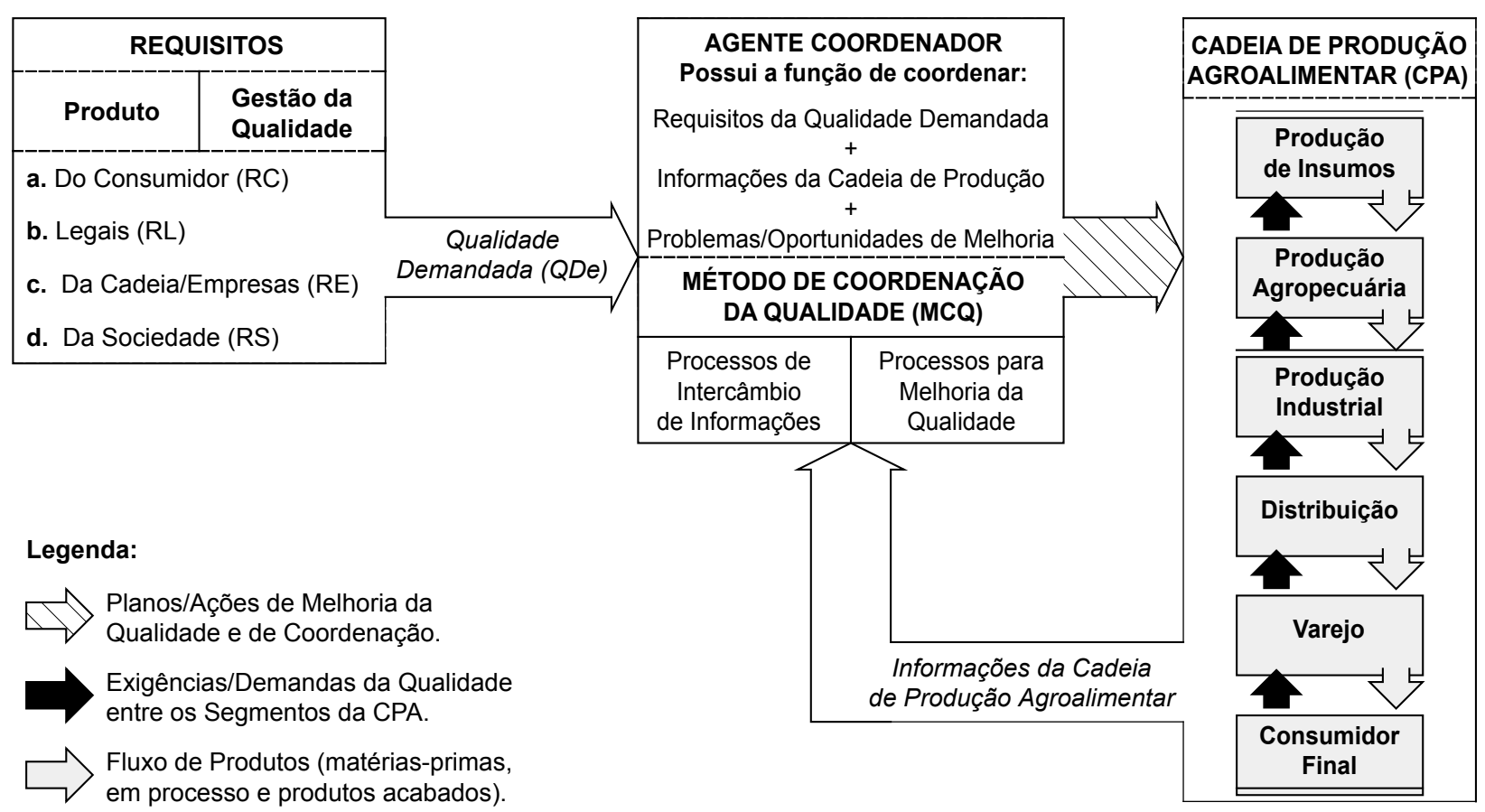

Figura 2. Visão geral dos elementos da estrutura para coordenação da qualidade. Fonte: Elaborado pelos autores.

Já os RGQ podem ser descritos como sendo o conjunto de requisitos necessários para planejar, executar e controlar atividades que buscam garantir que os projetos, processos, produtos e serviços elaborados pela CPA satisfaçam, ao máximo, as necessidades e expectativas do consumidor final e de seus próprios agentes. Os RGQ dizem respeito às práticas que os agentes da CPA adotam, tais como identificação e rastreabilidade de produtos, Boas Práticas Agrícolas, de Higiene e Fabricação, utilização do sistema de Análise de Perigos e Pontos Críticos de Controle (APPCC), inspeção e controle de processos, etc.

Por sua vez, a Qualidade Demandada (QDe) é composta pelos Requisitos Legais (RL), Requisitos do Consumidor (RC), os Requisitos da Cadeia/Empresas ou Requisitos das Empresas (RE) e os Requisitos da Sociedade (RS), cujas definições são mostradas no Quadro 2. A QDe deve refletir os aspectos contratuais e mercadológicos internos e externos à cadeia, abrangendo as necessidades e as expectativas explícitas e implícitas dos consumidores finais e clientes, ao longo da cadeia produtiva.

A QDe constitui o ponto de partida de aplicação do Método de Coordenação da Qualidade (MCQ), que é o elemento da ECQ abordado na próxima subseção.

\subsection{O Método de coordenação da qualida- de (MCQ)}

O instrumento que auxilia no processo de coordenação da qualidade deve ser capaz de:

a) receber, armazenar e enviar informações entre os agen- tes da CPA e o agente coordenador;

b) receber e armazenar informações do ambiente institucional;

c) tratar as informações recebidas e gerar diagnóstico a respeito da qualidade de produto e processo praticada pela CPA;

d) disponibilizar informações que possibilitem a tomada de decisão do agente coordenador;

e) capacitar o agente coordenador para elaboração de planos de ação e controle destes, quando implantados junto aos agentes da CPA; e

f) proporcionar visão holística, detalhada e precisa das ações praticadas pelos agentes da CPA, quanto às práticas de gestão da qualidade.

Tal instrumento, aqui denominado Método de Coordenação da Qualidade (MCQ), tem a função básica de auxiliar o agente coordenador a organizar, processar e analisar informações, sobre a qualidade dos produtos e sobre a gestão da qualidade praticada pelos agentes dos segmentos da cadeia, e estabelecer um fluxo de informações, entre o agente coordenador e as empresas, com o intuito de possibilitar um ciclo contínuo de melhoria.

O MCQ procura fornecer como produto de sua aplicação um conjunto básico de 3 categorias de informações:

a) requisitos de qualidade do produto e de gestão da qualidade que cada segmento da cadeia precisa atender;

b) diagnóstico da qualidade do produto e da gestão da qualidade nas empresas envolvidas, ou seja, identifica- 
Quadro 2. Tipos de requisitos da qualidade.

\begin{tabular}{cl}
\hline Tipos de Requisitos da Qualidade & \multicolumn{1}{c}{ Definição } \\
\hline Requisitos Legais (RL) & $\begin{array}{l}\text { Conjunto de normas, regulamentos, códigos e procedimentos formalizados } \\
\text { por legislação e que possam influenciar ou definir as características da } \\
\text { qualidade de um produto. } \\
\text { Consistem nos desejos e expectativas em relação a um determinado produ- } \\
\text { to a ser entregue ou serviço a ser prestado por um fornecedor. }\end{array}$ \\
Requisitos da Cadeia/Empresas (RE) & $\begin{array}{l}\text { Expressam as necessidades ou prioridades destas, explicitadas em termos } \\
\text { quantitativos ou qualitativos, objetivando definir características que o }\end{array}$ \\
& $\begin{array}{l}\text { produto deve conter, alinhadas às estratégias competitivas e de imagem da } \\
\text { empresa e da cadeia. }\end{array}$ \\
& Conjunto de normas, regulamentos, códigos, procedimentos, fatores de \\
Requisitos da Sociedade (RS) & saúde, de segurança, do meio ambiente e de conservação de energia, for- \\
& malizados por legislação ou praticados como valores sócio-culturais.
\end{tabular}

ção do que está ocorrendo na prática; e

c) desempenho, problemas, oportunidades e ações de melhoria na cadeia.

De modo geral, constituem exemplos de informações oriundas da aplicação do método: o nível de competitividade da cadeia medido por índices de desempenho, tipos e quantificação de falhas e perdas, falhas na gestão da qualidade, recomendações e formas de aplicação de planos de melhoria, controle dessa aplicação e avaliação dos resultados. Por possuir uma natureza dinâmica - pelo fato de ser resultado da análise de informações provindas de diversas fontes e seguir para diversos destinos - é fundamental que esse conjunto básico de informações seja distribuído por toda a cadeia de produção.

A recepção dos dados, bem como sua avaliação e posterior distribuição, devem ser entendidas como algo dinâmico, cíclico e de fluxo contínuo, entre as fontes de dados e informações, o agente coordenador e todos os segmentos da cadeia de produção.

Uma primeira tarefa do MCQ seria a de traduzir os diferentes componentes da qualidade demandada em requisitos de produto e de gestão que norteiem as operações, de modo a gerar produtos que satisfaçam as exigências da qualidade demandada.

O MCQ, no decorrer de seu aprimoramento e operacionalização, gerará um sistema de informação gerencial informatizado (SIGi) para uso dos agentes da CPA. Tal SIGi viabilizará a troca constante de informações entre as fontes de informação, a cadeia e o agente coordenador. $\mathrm{O}$ MCQ proposto é formado por oito módulos:

$\mathrm{O}$ módulo 1 tem por principal função identificar e agregar os requisitos da sociedade (RS), legais (RL), do consumidor (RC), da cadeia de produção e empresas que a compõem (RE) e transformá-los em uma "lista" de requisitos demandados. A essa lista é dado o nome de Qualidade Demandada (QDe), a qual deve refletir os aspectos contratuais e mercadológicos internos e externos à cadeia, abrangendo as necessidades e as expectativas explícitas e implícitas dos consumidores finais e clientes, ao longo da cadeia produtiva. A função da qualidade demandada seria a de indicar as características da qualidade do produto que devem ser buscadas e alcançadas de forma integrada pelas empresas de cada segmento da cadeia, garantindo, assim, a qualidade dos produtos intermediários e do produto final. Também é função deste módulo, verificar se existem requisitos conflitantes ou se um engloba algum outro. No caso de requisitos idênticos, elimina-se a duplicidade e em caso de requisitos que abrangem outros, mantém-se o mais abrangente. Dos requisitos dessa lista, define-se quais são os requisitos mais significativos ou características-chave que serão objetos de coordenação e que, portanto, deverão ser desdobradas no módulo 2. Por fim, é também neste módulo que são medidos os indicadores de desempenho da CPA, para posterior reavaliação no módulo 8 . A base tecnológica desse módulo seria composta por ferramentas e métodos para pesquisa de mercado e mecanismos para obtenção e organização de dados gerenciais.

O módulo 2 é executado em duas etapas. A primeira tem a função de desdobrar a QDe nos requisitos de qualidade de produto (RQP) e de gestão da qualidade (RGQ). Em outras palavras, significa identificar os "o quê" a serem buscados pela CPA e "como" esses "o quê" devem ser alcançados e gerenciados. A segunda etapa deste módulo tem a função de identificar e armazenar em diferentes bancos de dados, os "o quê" e "como" a serem empregados em cada segmento da CPA e que foram gerados na etapa 1. Uma ferramenta que poderia ser utilizada neste módulo é o Sistema de Desdobramento da Função Qualidade, ou Quality Function Deployment (QFD). Buscarse-á que o resultado desse módulo, conjunto de "o quê" e de "como" fundamentais, seja comunicado à cadeia de produção e a cada segmento responsável por cumpri-los.

O módulo 3 consiste num "módulo de ajuste" que tem como função eliminar incompatibilidades entre os "o quê" e "como" identificados no módulo anterior. Após o 
envio do resultado do módulo 2 para os segmentos da cadeia de produção, estes devem avaliá-los e indicar quais os válidos e aqueles que não são factíveis de realização, seja por problemas financeiros, técnicos, de pessoal, etc. Se necessário, os segmentos da CPA podem modificar ou acrescentar os "o quê" e "como" que forem necessários.

A eliminação ou acréscimo de certos "o quê" e "como", por um determinado segmento da CPA, pode causar problemas de conformidade para um segmento anterior ou posterior a esse. Por exemplo, no caso de uma cadeia de produção de leite UHT, se o segmento de produção leiteira, visando o aumento de produtividade por animal, decide mudar a dieta animal para uma ração com índices de hormônio mais elevados (supondo ser legalmente permitido), isso pode causar conflitos com o setor industrial, ao pretender, por exemplo, vender ao consumidor final um leite UHT isento de residual hormonal. Logo, é função do módulo 3 indicar os conflitos ao agente coordenador e auxiliá-lo nos contatos com as empresas dos segmentos envolvidos, em busca de um acordo. Após o ajuste, os resultados são enviados aos segmentos responsáveis por cada conjunto de "o quê" e "como" para nova avaliação, repetindo-se este processo até se conseguir um conjunto ajustado de "quês" e "comos" ao longo da cadeia. Portanto, o resultado do módulo 3 indica qual deve ser o "caminho correto" para satisfazer a QDe, ou seja, indica o quê deve ser buscado e como isso pode ser alcançado pelas empresas de cada segmento da CPA.

Entretanto, esse "caminho correto" já pode estar sendo praticado ao longo da cadeia. Cabe, então, ao módulo 4, verificar se os requisitos de qualidade de produto e de gestão da qualidade, já utilizados por cada segmento da cadeia de produção, correspondem ao "caminho correto" indicado pelo módulo 3. Essa verificação é realizada confrontando as características de produto e de gestão que seriam ideais e indicadas pelo MCQ com as características equivalentes, que estão sendo praticadas no momento pelas empresas da CPA. No caso de alguma característica, na prática, apresentar diferença em relação ao ideal, diz-se que existe um desvio, ou de requisito de produto ou de gestão da qualidade. Tanto o módulo 3 quanto o módulo 4 são constituídos basicamente por bancos de dados e, nessas etapas, o agente coordenador e as empresas da CPA desenvolvem uma importante e fundamental função de análise e geração de dados e informações.

O módulo 5 tem por função "listar" os desvios identificados no módulo 4, identificar suas causas e os segmentos responsáveis por elas, e medir os itens de verificação e de controle das etapas críticas de produção para cada segmento da CPA. Após essa medição, passa-se a informação gerada ao módulo 6 . O módulo 5 é constituído por bancos de dados e por ferramentas, como os diagramas de Causa-e-Efeito, de Relações e de Afinidades.
O módulo 6 tem por função analisar as causas dos desvios identificados no módulo 4 e listados no módulo 5, e propor planos de ação para a eliminação de tais desvios e de suas causas. Essa análise e geração de planos de melhoria são feitos a partir da aplicação de métodos e ferramentas da qualidade, aplicados junto aos segmentos causadores dos desvios.

Já o módulo 7 tem por função comunicar os resultados do módulo 6 aos segmentos da cadeia de produção, além de executar as funções de controle da implantação dos planos de ação de melhoria da qualidade, por parte dos segmentos da cadeia envolvidos. A avaliação da eficácia dos planos de ação é feita com nova medição dos índices de desempenho da cadeia e de sua confrontação com a primeira medição realizada durante a execução do módulo 1 do MCQ, para corroborar a aplicação dos planos propostos ou até mesmo transformá-los em processos operacionais padrão. Se durante tal avaliação forem observadas anomalias, ou seja, variabilidade indesejável nos itens de controle da CPA, deve-se identificar quais são as possíveis causas responsáveis por essa variabilidade, reiniciando a aplicação dos módulos 6 a 7 do MCQ. Neste módulo poderia ser utilizado o método PDCA/MASP.

Finalmente, é função do módulo 8 a auto-avaliação do próprio método de coordenação. Periodicamente, alguns fatores de avaliação são analisados, sendo passíveis de aprovação ou não. Se houver a plena aprovação de tais fatores, ou seja, se para todos os fatores a resposta for "sim", o MCQ segue sendo utilizado normalmente, caso contrário, o MCQ é analisado e são descobertas as falhas que devem ser sanadas, de modo que o método seja aperfeiçoado até atingir a plenitude de aprovação em sua auto-avaliação.

A Figura 3 demonstra as relações existentes entre o agente coordenador, o MCQ e a CPA, ressaltando a troca constante de informações entre os segmentos da cadeia de produção e o agente coordenador, bem como a situação dos elementos fundamentais da ECQ.

Como é possível observar na Figura 3, os módulos do MCQ são classificados como executores de Processos de Intercâmbio de Informações (PII) ou como executores de Processos para Melhoria da Qualidade (PMQ). Os PII, basicamente, nos módulos do MCQ, têm a função principal de estabelecer o intercâmbio contínuo de informações entre o agente coordenador e os agentes de todos os segmentos da CPA. Logo, tais módulos capturam, transformam e transmitem dados e informações entre todos os elementos constituintes da ECQ. Aqui se enquadram os módulos 1 e 7 do MCQ (Figura 3).

Os demais módulos do MCQ, ou seja, os módulos 2 a 6 mais o módulo 8, têm a função principal de servir como instrumento de apoio, para que o agente coordenador e os agentes da CPA possam analisar e utilizar os dados e 


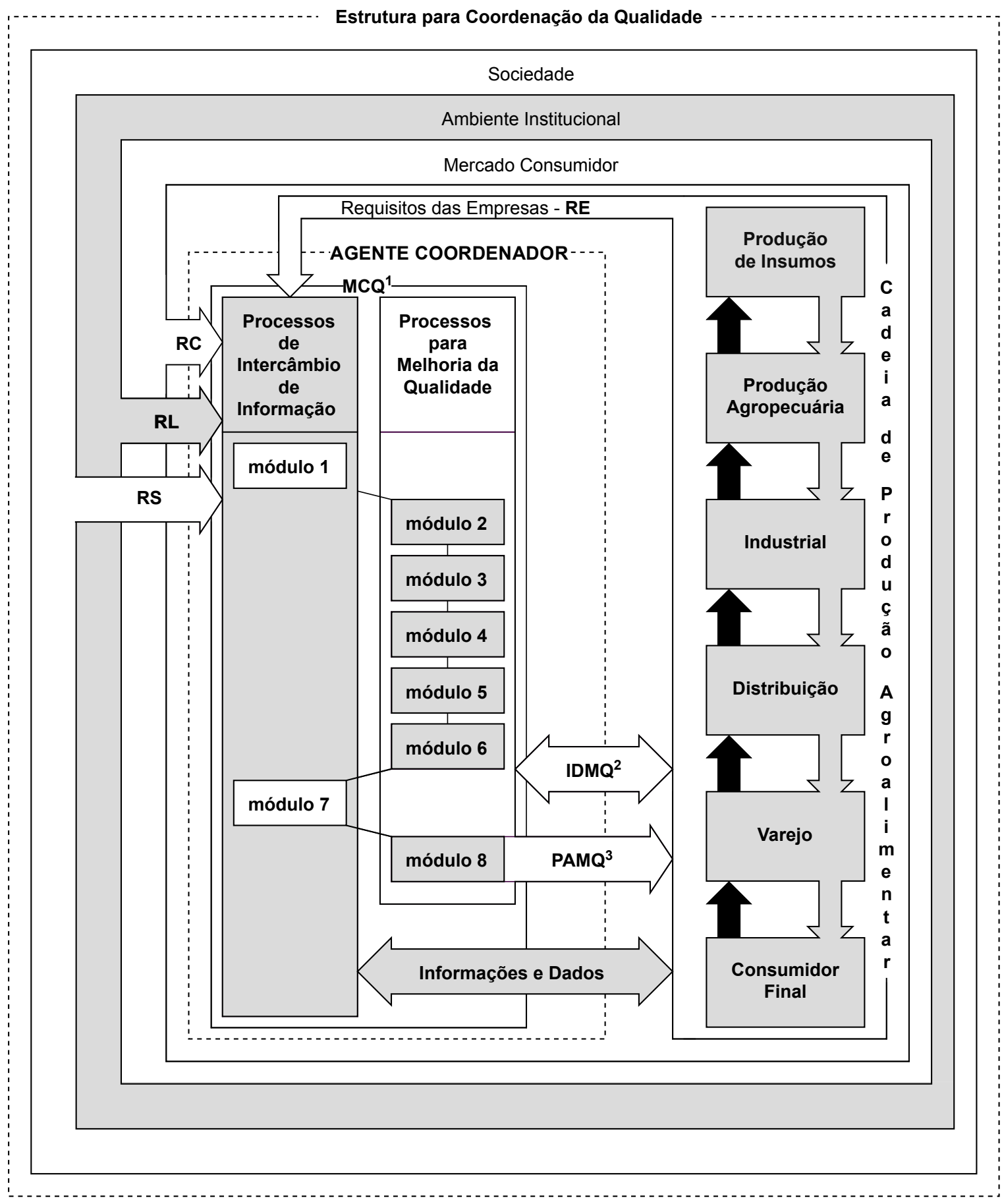

(1) MCQ: Método para Coordenação da Qualidade.

(2) IDMQ: Informações e Dados de Melhoria da Qualidade.

(3) PAMQ: Planos de Ação para a Melhoria da Qualidade (produtos + processos) e de sua Gestão.

Figura 3. O Método de coordenação da qualidade (MCQ) e os Elementos da Estrutura para Coordenação da Qualidade (ECQ). Fonte: Elaborado pelos autores.

informações intercambiados entre os elementos da ECQ (Figura 3).

Esse intercâmbio de dados e informações permite a geração de planos de ações para melhoria da qualidade do produto e de gestão da qualidade a serem implementadas pelos agentes da CPA e controladas pelos mesmos e pelo agente coordenador, tendo a finalidade de reduzir perdas e custos de produção, garantir a qualidade do produto final e incrementar a competitividade de toda a cadeia produtiva.

A composição dos recursos tecnológicos do MCQ pouco varia de um módulo para outro, mas o grau de utilização 
desses recursos determina a diferença entre quais seriam os componentes tecnológicos fundamentais para os módulos executores de PII e para os executores de PMQ.

\subsection{O Agente coordenador: estrutura e funçỗes}

Segundo Zylbersztajn (1995), como os sistemas agroindustriais são sujeitos a choques e pressões que requerem respostas coordenadas, espera-se que as estruturas de governança híbrida (contrato) ou hierárquica (integração vertical) sejam as mais adotadas nestes sistemas. Para o mesmo autor, nos casos em que haja necessidade de ajustamentos de coordenação estrita para adaptação das cadeias de produção, envolvendo um grande número de agentes, motiva-se o surgimento de organizações com o intuito de realizar o papel de agente coordenador. Tal agente é discutido nesta subseção, indicando seu perfil e principais funções na coordenação da qualidade.

Quanto ao perfil demandado para esse elemento da ECQ, o agente coordenador poderia ser: uma empresa de um segmento da própria cadeia, um grupo de profissionais constituído por representantes de cada segmento da CPA, uma empresa independente organizada e contratada para exercer tal função, uma instituição governamental, ou uma associação representativa da cadeia de produção em questão.

Como o método proposto (MCQ) é um instrumento de apoio à função de gerenciamento do agente coordenador, cabe a ressalva de que é fundamental a definição de uma estrutura de governança adequada, para que ele consiga integrar o MCQ em suas tarefas e integrar-se o mais eficientemente possível com os segmentos da cadeia produtiva. Nesse sentido, o agente coordenador poderia executar um papel na CPA semelhante ao assumido pela
Autoridade de Segurança Alimentar da União Européia (EFSA), a qual foi criada para garantir um nível elevado de proteção à saúde dos consumidores. A Comissão das Comunidades Européias (CCE) declara que "o papel de uma Autoridade de Segurança Alimentar deve ser definido no contexto do processo de análise dos riscos, que abrange a avaliação, a gestão e a comunicação dos riscos" (CCE, 2000, p.16). As funções do agente coordenador são apresentadas na Figura 4.

As funções do agente coordenador, apresentadas na Figura 4, podem ser descritas como:

a) Gerenciamento do Sistema de Informações: esperase que o Agente coordenador gerencie o Sistema de Informações no que tange a:

1. Requisitos da Qualidade do Produto (RQP) final (estabelecer quais são esses requisitos para o produto que é oferecido ao final da cadeia de produção);

2. Requisitos da Qualidade do Produto para cada segmento da cadeia de produção (estabelecer quais são esses requisitos para cada uma das empresas pertencentes a cada segmento da cadeia de produção);

3. Requisitos de Gestão da Qualidade (definir quais as práticas, para diagnóstico e melhoria da gestão da qualidade, deverão ser desenvolvidas e aplicadas, tanto na cadeia como para cada segmento da cadeia de produção);

4. Situação atual do atendimento dos RQP (avaliar se os requisitos da qualidade estabelecidos - tanto para o produto final como para o produto ao longo dos segmentos da cadeia de produção - estão sendo atendidos na realidade);

5. Situação atual da aplicação das práticas de Gestão da

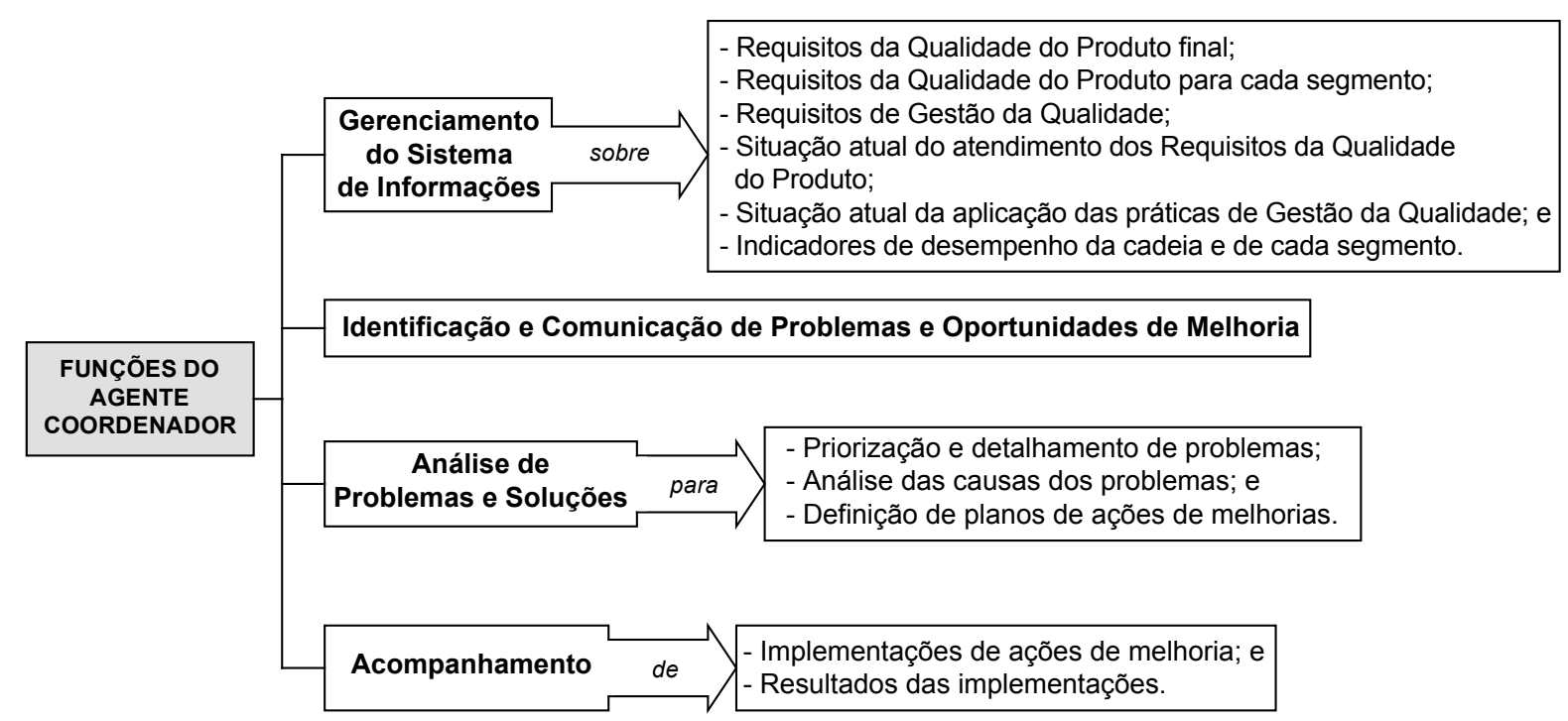

Figura 4. Funções do agente coordenador na cadeia de produção agroalimentar. Fonte: Elaborado pelos autores. 
Qualidade (avaliar se as práticas que devem ser aplicadas, realmente estão sendo aplicadas no dia-a-dia das empresas dos segmentos da cadeia de produção); e

6. Indicadores de desempenho da cadeia e de cada segmento (medir o desempenho - o grau de atendimento de resultados pretendidos ao longo do tempo - tanto para cada segmento da CPA como para a própria cadeia como um todo).

b) Identificação e Comunicação de Problemas e Oportunidades de Melhoria: o Agente coordenador, com base nas informações que gerencia (vide acima), deve identificar a ocorrência de desvios (problemas) e, além disso, identificar oportunidades de melhorar a realidade atual, mesmo que nenhum problema seja identificado. Mas não basta identificá-los, é fundamental compartilhar isso com todos os segmentos da cadeia, de modo a sinalizar para cada um deles, onde há problemas e onde há possibilidade de investir em melhorias;

c) Análise de Problemas e Soluções: espera-se que o agente coordenador organize reuniões periódicas junto aos representantes de cada segmento da cadeia de produção, nas quais, a partir da priorização e do detalhamento dos problemas identificados, são analisadas as causas fundamentais dos problemas identificados e também são planejadas, em conjunto, ações de melhoria tanto para atuar nessas causas, buscando soluções de tais problemas, como para aproveitar as oportunidades de melhoria levantadas; $\mathrm{e}$

d) Acompanhamentos: mais do que simplesmente propor ações de melhoria, é fundamental que estas sejam realmente implantadas na prática. Assim, é preciso que o Agente coordenador viabilize meios de acompanhar a implantação dessas ações propostas, verificando se os resultados esperados estão sendo obtidos e, também, se tais ações não estão causando efeitos colaterais nas empresas dos segmentos ou na cadeia de produção como um todo.

Um exemplo prático de organização, que desempenha as funções de um agente coordenador, são as interprofesionales ou inter-profissionais espanholas, ou seja, ser uma instituição constituída por representantes dos diversos segmentos da cadeia de produção. Tais organizações são entendidas como "entidade constituída por organizações representativas dos empresários da produção, da transformação e da comercialização de um serviço ou produto incluído dentro do sistema agroalimentar" (MAPA, 2003).

\section{Recomendações para implantação da estrutura de coordenação da qualidade}

A ECQ proposta pode ser implantada nas mais diversas cadeias de produção agroalimentares, considerando-se suas especificidades, potencialidades e desafios. Afinal, todas as cadeias teriam em comum, do pondo de vista da aplicação da ECQ, fatores como:

- requisitos de qualidade do produto a serem atendidos;

- práticas de gestão da qualidade a serem adotadas;

- necessidade de redução de custos de perdas e de falhas;

- necessidade de integração das informações sobre o desempenho em qualidade;

- a qualidade do produto final (a qualidade experimentada pelo consumidor) como resultante de ações em cada segmento;

- a interdependência da qualidade de cada segmento com os demais;

- a necessidade de gerar e preservar a qualidade ao longo de toda a cadeia;

- objetivos de qualidade da cadeia que podem ser compartilhados por todos os agentes envolvidos; e

- a necessidade de formulação e implementação coordenada de planos de melhoria.

Considerando-se a implantação da ECQ numa CPA específica, sugere-se que esta ocorra segundo duas fases: uma de "adequação" e outra de "implantação", conforme apresentado na Figura 5.

A fase de "adequação" consiste basicamente num período de preparação dos agentes ligados à CPA em questão para a implantação da ECQ. Assim sendo, elencamse as seguintes atividades subseqüentes como condições necessárias para a implantação da ECQ numa CPA:

1 - Compreender a ECQ e seus elementos (o que incluí o método de coordenação), ou seja, os agentes pertencentes à cadeia ou ligados a ela devem entender a importância da ECQ, os objetivos, bem como sua dinâmica de funcionamento na CPA;

2 - Definir e organizar o agente coordenador, definindo sua estrutura e seu perfil de atuação, dentre as possibilidades apontadas no item 4.3 deste artigo. É ele quem vai liderar as atividades de coordenação da qualidade na CPA, e sua indicação adequada é fundamental para o sucesso da implantação da ECQ;

3 - Efetuar um diagnóstico da CPA, visando analisar as necessidades e desafios do ambiente econômico, tecnológico e institucional da cadeia;

4 - Discutir e estabelecer os objetivos da CPA, bem como as estratégias competitivas para atingi-los;

5 - Definir os objetivos e o escopo da coordenação da qualidade, bem como as características de qualidade a serem coordenadas;

6 - Adequar a ECQ às especificidades da CPA em questão; e

7 - Definir a capacitação mínima necessária que cada segmento da CPA deve ter para participar do processo de implantação da ECQ, tanto em termos de ações internas 


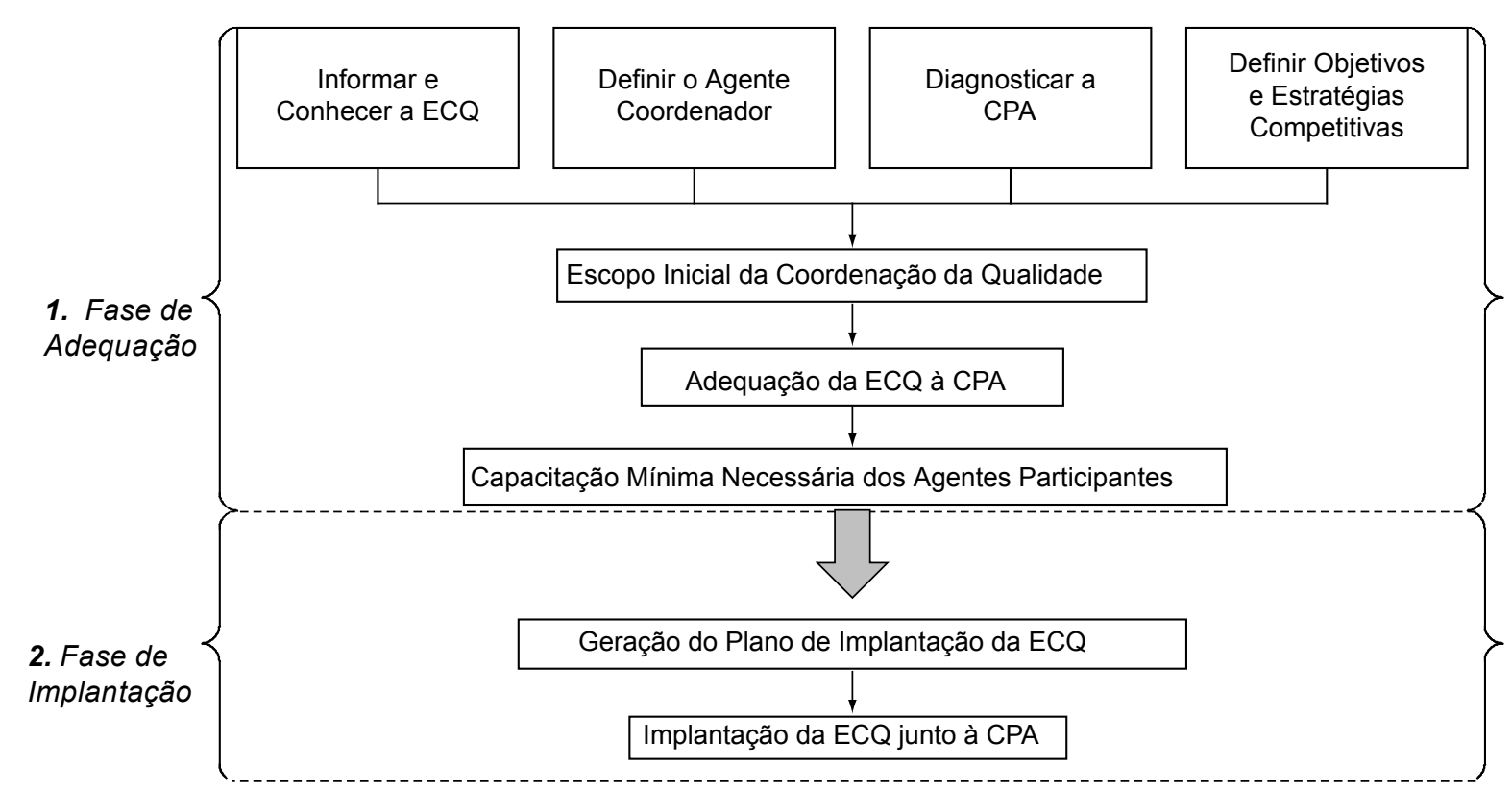

Figura 5. Fases de Implantação da Estrutura de Coordenação da Qualidade. Fonte: Elaborado pelos autores.

à empresa como de ações comuns à cadeia.

Uma vez realizadas essas atividades, espera-se que a CPA esteja preparada para iniciar o processo de implantação propriamente dito.

Dada a heterogeneidade entre os agentes da CPA, em termos de conhecimento e de adoção de tecnologias e práticas de gestão da qualidade, sugere-se que a implantação da ECQ seja planejada segundo "estágios de maturidade".

Por "estágio de maturidade" entende-se o nível em que a ECQ se encontra, durante seu processo de implantação na CPA, em relação aos seguintes aspectos:

- escopo da ECQ: definido em termos da quantidade de segmentos da CPA e respectivos agentes que participam da implantação, bem como da quantidade de requisitos (RQP e RGQ) que são coordenados;

- nível de detalhamento das informações trocadas entre o agente coordenador e a CPA;

- nível de organização do agente coordenador (o quão desenvolvida está sua estrutura interna) e o grau de complexidade das atividades de coordenação da qualidade na CPA;

- nível de capacitação demandada, tanto para os segmentos e respectivos agentes da CPA como para o próprio agente coordenador; e

- módulos do MCQ que estão implantados no dia-a-dia da CPA.

Ainda durante o processo de implantação, é importante que os agentes participantes realizem, periodicamente, uma avaliação, indicando seus pontos positivos e dificuldades encontradas, de modo a construir um conjunto de lições aprendidas, as quais poderão ser proveitosas, seja para a melhoria da eficácia da implantação em andamento, seja como referência para outros processos de implantação da ECQ em outras cadeias.

Implantar a ECQ em uma CPA não é tarefa trivial, podendo-se prever muitas dificuldades, sobretudo aquelas derivadas do desnível existente entre os agentes (entre segmentos distintos ou mesmo dentro de um mesmo segmento da CPA) em termos de capacitações e da adoção de tecnologias e práticas de gestão da qualidade.

Discutem-se, a seguir, algumas questões pertinentes à viabilidade de implantação da ECQ e do MCQ em uma $\mathrm{CPA}$. Espera-se que os benefícios à CPA sejam crescentes à medida que:

(1) aumente o tempo de uso do método por seus agentes; e

(2) aumente o número de agentes da cadeia que se adequem às exigências mínimas necessárias para sua integração ao ECQ e possibilidade de uso do MCQ.

Com esses aumentos, os agentes da CPA passam a tratar a qualidade como fator estratégico para a cadeia e de vantagem competitiva junto ao mercado consumidor. A melhor compreensão da QDe e o comprometimento de todos os segmentos da cadeia em satisfazê-la, reduziria as perdas geradas pela não-qualidade, notadamente as geradas por falhas de produção, necessidade de retrabalho, sub-aproveitamento de recursos de transformação e a serem transformados, etc. Como resultado, os agentes seriam capazes de identificar novos nichos de mercado, ao mesmo tempo que aumentariam sua quota de mercado nos quais a CPA já atua.

Segundo Gallego et al. (2003), o incremento no nível da qualidade, de modo geral, aumenta (a) a produtividade das empresas e (b) a satisfação dos clientes. $\mathrm{O}$ aumento 
da produtividade permite reduzir os custos de produção e o preço ao cliente. O aumento da satisfação dos clientes pode permitir um acréscimo no preço do produto ofertado, como recompensa à maior confiança gerada no mercado. Em ambos os casos, o resultado final é o incremento da quota de mercado e consequiente incremento dos benefícios conquistados pela CPA e seus agentes (Figura 6).

Já com relação aos custos de implantação da ECQ e do MCQ, estes podem ser divididos em três categorias:

(1) custos de projeto e adequação da ECQ/MCQ à CPA;

(2) custo de implantação da ECQ/MCQ; e

(3) custo de operação da ECQ/MCQ.

Os custos iniciais de adaptação tecnológica e gerencial da CPA são amortizados ao longo do tempo. O aprendizado organizacional reduzirá os custos de projeto e adequação e de implantação junto a novos agentes da cadeia, além de reduzir os custos de operação junto a todos os agentes envolvidos. Na medida em que a ECQ/MCQ é utilizada, o incremento dos benefícios, gerado pela expansão da quota de mercado ou pela redução dos custos da não-qualidade, deverá compensar os custos de operação e manutenção.

\section{Ilustração do $M C Q: O$ caso do queijo minas frescal}

Tendo em vista as dificuldades de validar o modelo a curto prazo junto a uma cadeia, devido ao tempo necessário para implantação e medição de resultados, optou-se por apresentar aqui uma ilustração para demonstrar sua aplicabilidade. A ilustração objetiva exemplificar a dinâmica do MCQ numa cadeia de produção, neste caso, na cadeia do queijo minas frescal. Essa cadeia é utilizada como exemplo, pois, apesar do produto ser pouco representativo em relação a outros produtos lácteos, é considerada uma das cadeias com potencial para crescimento de consumo, caso haja uma melhoria na qualidade do produto. A qualidade do queijo minas frescal, no que diz respeito à qualidade objetiva do produto, que compreende as características microbiológicas, físico-químicas e nutricionais, é considerada baixa, conforme pode ser observado no Quadro 3.

Esse tipo de queijo geralmente é fabricado por pequenos e médios laticínios. Devido à falta de barreiras tecnológicas para a sua produção, a fabricação é pulverizada em todo o país. Os procedimentos e equipamentos utilizados por essas indústrias são rudimentares e arcaicos, o que confere grande impacto na qualidade do produto final. No entanto, essas indústrias terão que se modernizar para atender às novas normas de produção e industrialização de produtos lácteos previstas na normativa 51 do Ministério da Agricultura. Com a necessidade de adoção do

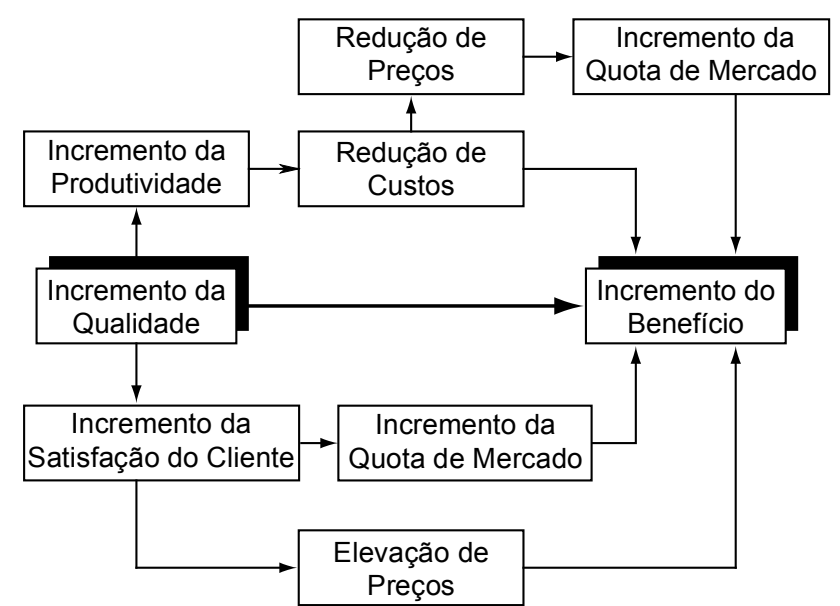

Figura 6. Benefícios Oriundos do Incremento da Qualidade. Fonte: Adaptado de Gallego et al. (2003, p. 13).

sistema de Análise dos Perigos e Pontos Críticos de Controle (APPCC), os procedimentos e as práticas de gestão da qualidade terão que ser reformulados ou criados.

A qualidade do queijo minas frescal é baixa em decorrência da precariedade higiênico-sanitária de todas as fases de produção: extração do leite, industrialização, distribuição e comercialização. Assim sendo, todos os agentes da cadeia devem seguir normas de procedimentos e práticas de gestão da qualidade, para obtenção de um produto final com qualidade assegurada.

A adoção da ECQ contribuiria para sanar muitos desses problemas. A seguir será demonstrado como poderiam ser utilizados tal estrutura e o MCQ na cadeia de produção do queijo minas frescal.

\section{Módulo 1. Identificação da qualidade demandada}

Para a produção do queijo minas frescal, a qualidade demandada pode ser desdobrada em dois grupos de requisitos: os do consumidor e os legais. Quanto aos requisitos do consumidor, podem ser consideradas as características da qualidade do queijo minas frescal como gostoso, saboroso, saudável, com embalagem fácil de abrir, de armazenar e de descartar. As características-chave que podem ser coordenadas são o gosto, sabor e segurança, já que o queijo minas, quando alterado, pode interferir nessas características, dependendo da origem do agente contaminante.

Já os requisitos legais do queijo minas frescal são referentes aos padrões ditados pelo Regulamento Técnico Para a Fixação de Identidade e Qualidade do Queijo Minas Frescal. São considerados requisitos legais do queijo minas frescal as características sensoriais, características físico-químicas, características microbiológicas e acondicionamento (embalagem). Como o objetivo é demonstrar a dinâmica do modelo e não o detalhamento dos requisitos legais, para maiores detalhes sobre esses requisitos pode ser consultado o site do Ministério da Agricultura: www.agricultura.gov.br/sda/dipoa 
Módulo 2: Desdobramento da qualidade demandada em requisitos de qualidade de produto e de gestão

Definidos os "o quê" que devem ser atendidos, esses requisitos devem ser desdobrados a todos os segmentos da cadeia (Quadro 4).

Posteriormente à definição das características de qualidade que devem ser atendidas pelos agentes da cadeia, deve ser definido como atingir essas características. Dessa forma, devem-se definir as práticas de gestão da qualidade que deverão ser adotadas pelos agentes da cadeia e as práticas de coordenação da qualidade. Como práticas de gestão da qualidade pode-se citar as Boas Práticas de Fabricação, a Análise dos Perigos e Pontos Críticos de Controle, o Monitoramento Integrado de Pragas. E, como práticas de coordenação da qualidade, pode-se citar a assistência técnica a fornecedores, o envolvimento do fornecedor no processo de desenvolvimento de novos produtos e premiação a distribuidores/varejistas pela preservação da qualidade.

Com relação aos fornecedores de leite às indústrias, algumas iniciativas já estão contribuindo para a melhoria da qualidade dos produtos lácteos, como a utilização de coleta de leite à granel e refrigerado, mas os problemas ainda persistem, pois dependem muito mais da conscientização das pessoas em adotar procedimentos adequados de higiene. Muitos produtores não sabem sequer os procedimentos mínimos de higiene na ordenha. Não higienizam as mãos, para a ordenha manual, nem os tetos das vacas, o que tem como conseqüência altos índices de contaminação microbiológica. Assim, na produção leiteira, poderiam ser utilizadas metodologias de gestão da qualidade como as Boas Práticas de Manejo e Higiene (BPMH) e um Programa de Higienização Ambiental (PHA). E, como práticas de coordenação da qualidade, poderiam ser utilizados o pagamento pela qualidade do leite e a assistência técnica ao produtor.

$\mathrm{Na}$ indústria de laticínios, os problemas em grande parte envolvem a mão de obra, já que a intervenção humana na manipulação do produto ainda é fortemente acentuada. Segundo Scalco (1999), apenas 3 dos vinte e um laticínios pesquisados que processavam acima de 50.000 litros diários no Estado de São Paulo, consideraram o treinamento da mão de obra fator prioritário para o controle da qualidade do processo. Conforme observado no Quadro 3, a contaminação por coliformes fecais se dá pela falta de higienização nas mãos de quem manuseia o produto, o que é um indicativo de mão de obra incapacitada para tal função. Dessa forma, algumas práticas de gestão, que poderiam resolver o problema de contaminação pela intervenção humana no processo de fabricação do queijo minas frescal são as Boas Práticas de Higiene (BPH), Boas Práticas de Fabricação (BPF), Procedimentos de limpeza e sanitização de equipamentos de pasteurização e produção de produtos derivados do leite e o Monitoramento Integrado de Pragas. A distribuição e comercialização do queijo é uma etapa crítica para a qualidade. Alguns caminhões refrigerados muitas vezes não estão com a temperatura devidamente controlada, e alguns pontos de venda não refrigeram devidamente os produtos.

Conseqüentemente, o produto chega ao consumidor final com baixa qualidade. Outro problema que também agrava a qualidade do queijo nos pontos de venda é a mão de obra. Muitas vezes os funcionários não são preparados e treinados para exercer a função de manipulação de produtos perecíveis. Não usam uniformes e luvas próprias para o manuseio do produto, não limpam adequadamente os utensílios que tem contato direto com o produto e, conseqüentemente, prejudicam a qualidade do produto final. Algumas práticas que podem ser utilizadas para controlar a qualidade na distribuição e comercialização são as BPF, BPH, Monitoramento Integrado de Pragas (MIP) e utilização de termômetros para conferência da temperatura. E, como prática de coordenação da qualidade, poderiam ser utilizadas, pela indústria com relação aos seus distribuidores, orientações para o manuseio do produto e premiações por serviços prestados para a preservação da qualidade do produto.

\section{Módulo 3: Ajustes}

Todas essas informações (requisitos de qualidade do produto e de gestão da qualidade) devem ser transmitidas por um agente coordenador, que, no caso da cadeia de produção de queijo minas frescal, poderia ser representado por um grupo de pessoas originado da produção leiteira, indústria, distribuição e ponto de venda (supermercado). Posteriormente à transmissão dessas informações,

Quadro 3. Qualidade de queijos de diferentes origens. Fonte: Santos (2001).

\begin{tabular}{|c|c|c|c|}
\hline Local & Produto & \% de produtos não conformes & Possíveis Razões \\
\hline S.J.Rio Preto & $\begin{array}{l}\text { Queijo Minas } \\
\text { Frescal }\end{array}$ & $96,65 \%$ (para padrões microbiológicos) & \multirow{3}{*}{$\begin{array}{l}\text { Condições higiênico-sanitárias } \\
\text { na produção leiteira e/ou no } \\
\text { processamento e/ou na distri- } \\
\text { buição e/ou comercialização. }\end{array}$} \\
\hline São Paulo & $\begin{array}{l}\text { Queijos de ambu- } \\
\text { lantes }\end{array}$ & $\begin{array}{l}100 \% \text { ( para temperatura) } \\
70 \% \text { inaceitável ao consumo humano }\end{array}$ & \\
\hline Goiás & $\begin{array}{l}\text { Queijo Minas } \\
\text { Frescal }\end{array}$ & $\begin{array}{l}43 \% \text { de presença de S.aureus e coliformes } \\
\text { fecais }\end{array}$ & \\
\hline
\end{tabular}


Quadro 4. Os "quês" para o Queijo Minas Frescal. Fonte: Scalco (2004).

\section{Mercadoria (ponto de venda) - Requisitos da Qualidade do Produto}

- Atributos físico-químicos da mercadoria: temperatura da mercadoria (se refrigerada);

- Atributos de embalagem: - rótulo: sem rasuras e boa visualização;

- Informações (nome do alimento; ingredientes, peso líquido e drenado; indústria, embalador, distribuidor, importador, exportador ou vendedor; país de origem; identificação do lote; data de fabricação e validade; instruções de armazenagem e uso;

- Integridade - sem deformações (estufamento, amassos, cortes); e

- Atributos organolépticos da mercadoria (cor, sabor, odor, textura, aparência).

Mercadoria (distribuidor) - Requisitos da Qualidade do Produto

- Atributos físico-químicos da mercadoria: temperatura da mercadoria (se refrigerada); e

- Atributos de embalagem (idem aos requisitos no ponto de venda).

Produto Industrial (processamento) - Requisitos da Qualidade do Produto

- Atributos físico-químicos do produto industrial (temperatura, sujidades, toxinas, resíduos químicos, composição (gordura, proteína, sólidos totais), e algumas específicas a alguns produtos como: umidade (para leite em pó e manteiga), solubilidade, partículas queimadas e dispersabilidade (para o leite em pó), índice de peroxidade (para a manteiga), estabilidade ao etanol (para o leite uht) e viscosidade (para iogurtes e bebidas lácteas);

- Atributos organolépticos do produto industrial (cor, sabor, odor, textura, aparência);

-Atributos microbiológicos (Contagem Total de microorganismos (C.T): mesófilos, psicotróficos (coliformes), estafilococos coagulase-positivo, salmonella sp, bacillus cereus, listeria monocytogeneses, bolores e leveduras; e

- Atributos da embalagem (tamanho, forma, praticidade, proteção, reciclável, manuseio e idem aos requisitos de embalagem especificados no ponto de venda).

\section{Matéria-Prima (produção pecuária) - Requisitos da Qualidade do Produto}

a) Atributos físico-químicos do leite cru refrigerado:

- gordura: mínimo 3 gramas/100 gramas de leite (g/g de leite);

- densidade relativa: 1,028 a $1,034 \mathrm{~g} / \mathrm{ml}$ de leite;

- índice criscópico: - 0,530 a 0,550 $\mathrm{H}$;

- sólidos não gordurosos: mínimo 8,4 g/100 g de leite;

- proteína total: mínimo 2,9 g/100 g de leite;

- inibidores* (ver anexo 2 - LMR em relação aos grupos de antibióticos); e

- temperatura: $4^{\circ} \mathrm{C}$

b) Atributos microbiológicos de leite cru refrigerado:

- Presença de microorganismos indesejáveis ao leite, utiliza-se um dos três testes químicos e rápidos para se averiguar: redutase: mínimo 3:30 horas (para leite B) e mínimo 90 minutos (para leite C); estabilidade ao alizarol 72\%: estável; e acidez real 0,14 a 0,18 g de ácido láctico/ml de leite - PH entre 6,6 e 6,8.

c) Testes microbiológicos como:

- UFC* (unidades formadoras de colônias): máximo 5× $100000 \mathrm{UFC} / \mathrm{ml}$ de leite; e

- CCS*: (contagem de células somáticas): $1000000 \mathrm{cs} / \mathrm{ml}$ de leite.

$(*)$ verificar esses requisitos duas vezes por mês, por produtor.

esse grupo deve realizar os ajustes necessários, ou seja, verificar a viabilidade da adoção dos requisitos quanto ao custo, pessoal e recursos técnicos. Também deve ser observada a necessidade de adoção de práticas de coordenação que possibilitem o desenvolvimento da cadeia para a melhoria da qualidade do produto final, como por exemplo, parcerias, assistências técnicas, prestação de serviços, entre outros.

\section{Módulo 4: Acompanhamento}

Realizados os ajustes, o agente coordenador deve acompanhar o desempenho de toda a CPA, a fim de verificar se os agentes estão se adequando aos requisitos. 
Indicadores de Desempenho devem ser utilizados para o acompanhamento da qualidade do produto, como por exemplo, a taxa de produtos não-conformes. Os procedimentos e práticas de gestão da qualidade também devem ser acompanhados a partir dos requisitos de gestão da qualidade por meio de um check-list. Por exemplo, a utilização do PHA na produção leiteira pode ser verificada a partir da observação se o local de produção está mantido limpo e arejado.

\section{Módulo 5: Identificação de problemas}

Caso o agente coordenador verifique problemas, esses devem ser solucionados por ordem de prioridade. Os problemas prioritários devem ser analisados, estudando detalhadamente as possíveis causas, como, por exemplo, ambiente, mão de obra, equipamento, método e matéria-prima. Para o levantamento e discussão das possíveis causas, pode-se utilizar como ferramenta o diagrama de Ishikawa.

Módulo 6: Planos para a solução de problemas e ações de melhoria

Identificada(s) a(s) causa(s) do problema, o agente coordenador elabora planos para a solução do problema e para a melhoria. Esses planos alternativos devem ser discutidos e aprovados, entre os agentes envolvidos.

Módulos 7 e 8: Comunicação e controle dos planos de ação de melhoria

Por fim, os agentes devem ser comunicados das ações planejadas e que serão executadas. Posteriormente o agente coordenador deve acompanhar a evolução das ações executadas. Para que a coordenação da qualidade tenha sucesso na sua implementação, todos os envolvidos (agentes) devem desenvolver uma visão sistêmica da cadeia e entender que, tanto o seu cliente como o seu fornecedor, são parceiros para a melhoria da qualidade do produto final.

\section{Considerações finais}

O principal desafio para a coordenação da qualidade ao longo de uma CPA está na capacidade de estabelecer uma relação de cooperação entre os agentes da cadeia, a qual pode ser entendida como a reunião de empresas interdependentes que agem juntas para gerenciar os fluxos de produção, de serviços e de informações na cadeia, a fim de satisfazer o consumidor final e minimizar custos.

A proposta apresentada constitui uma forma de coordenação baseada numa concepção sistêmica da qualidade, em que se substitui o controle interno e individual de cada segmento por uma coordenação por meio de uma estrutura e de um método orientados para a prevenção de falhas e de perdas e, também, para a melhoria da qualidade ao longo da CPA.

A estrutura e o método devem ser projetados como um mecanismo de incentivo e controle mais eficiente, para integrar e compartilhar informações e custos sobre qualidade, contribuindo para a competitividade da cadeia. Busca-se gerar a cooperação e participação na garantia da qualidade, de todos os envolvidos na cadeia de produção.

À medida que os padrões de qualidade tendem a ser definidos na própria cadeia ou de forma mista (público e privado), buscam-se mecanismos próprios intra-cadeia para acompanhamento e avaliação do atendimento a esses padrões, que é o sentido da proposta de estrutura de coordenação aqui apresentada.

Os atributos de qualidade e de gestão, que uma cadeia pretende sinalizar para o mercado, têm suas especificidades em função das categorias de produtos (bens de procura, de experiência e de crença). Entretanto, acredita-se que a aplicação do MCQ possa ser devidamente adequada para qualquer tipo de bem transacionado e de estrutura de governança dominante (mercado, mista e hierárquica). Uma vez que as transações de bens de crença têm uma importância crescente no sistema agroalimentar, o MCQ pode ser utilizado contribuindo na redução de diferenças entre os atributos de qualidade sinalizados e os efetivamente realizados, incrementando a confiança do consumidor.

Vale ressaltar que a aplicação do MCQ requer interação constante entre o agente coordenador, os segmentos da cadeia, instituições públicas e entidades de representação e de regulamentação e fiscalização. O envolvimento desse conjunto de diferentes tipos de organização pode dar à gestão da cadeia de produção um aspecto imparcial e de equilíbrio, entre os interesses de cada parte envolvida nesse processo de coordenação.

Reitera-se a expectativa de que o método proposto contribua para efetivamente garantir e, continuamente, melhorar a qualidade dos produtos ao longo da cadeia, com vistas à agregação de valor, à redução de perdas e de custos de produção e à segurança do alimento.

Para tanto, reforça-se a importância de que a estrutura e o método de coordenação estejam consolidados em termos da própria organização da cadeia de produção agroalimentar e seus segmentos; da correta identificação dos requisitos de qualidade e de gestão da qualidade dos clientes e do ambiente institucional; do seu desdobramento para os agentes participantes; do estabelecimento de um sistema de informações confiável e eficaz; da visão compartilhada de objetivos, indicadores de desempenho, problemas e planos de ações; bem como da atuação equilibrada e constante do agente coordenador com seu perfil pró-ativo e integrador.

Acredita-se que este trabalho possa enriquecer a literatura acadêmica e científica na área que enfatiza a "necessidade de se coordenar a cadeia de produção", uma vez que apresenta uma alternativa prática para essa coordenação. 
ASSUMPÇÃO, M. R. P. Reflexões para Construção de Metodologia para Desenvolvimento Sustentável na Cadeia de Suprimento: Adendo a relatório técnico apresentado à FAPESP - Departamento de Engenharia de Produção, Universidade Federal de São Carlos. São Carlos, 2002. 57 p.

BAINES, R. N.; DAVIES, W. P. Quality assurance in international food supply, In: INTERNATIONAL CONFERENCE ON CHAIN MANAGEMENT IN AGRIBUSINESS AND THE FOOD INDUSTRY, 3., 1998, Wageningen. Proceedings..., Wageningen: Wageningen Academic $\mathrm{Pu}-$ blishers ,1998. p. 213-223.

BECHTEL, C.; JAYARAN, J. Supply chain management: a strategic perspective, The International Journal of Logistics Management, v. 8, n. 1, p. 15-34, 1997.

BOEHLJE, M. et al. Observations on formation of food supply chains, In: INTERNATIONAL CONFERENCE ON CHAIN MANAGEMENT IN AGRIBUSINESS AND THE FOOD INDUSTRY, 3., 1998, Wageningen. Proceedings..., Wageningen: Wageningen Academic $\mathrm{Pu}-$ blishers, 1998. p. 393-403.

BORRÁS, M. A. A.; TOLEDO, J. C. de. A Proposal of Managerial Method to Assure the Final Product Quality into Agri-Food Supply Chains. In: ANNUAL WORLD FOOD \& AGRIBUSINESS FORUM AND SYMPOSIUM, 13., 2003, Cancún. Proceedings..., Cancún: International Food and Agribusiness Management Association, 2003. Disponível em: <http://www.ifama.org/conferences/ 2003Conference/papers.htm>. Acesso em: 25 out. 2004.

CCE - COMISIÓN DE LAS COMUNIDADES EUROPEAS. Libro Blanco sobre la Seguridad Alimentaria (relatório final) Bruxelas: A Comissão, 12 de jan. 2000.

EARLY, R. Guide to Quality Management Systems for the Food Industry. London: Blackie Academic and Professional, 1995. $306 \mathrm{p}$.

FROHLICH, M. T.; WESTBROOK, R. Arcs of integration: an international study of supply chain strategies. Journal of Operations Management, v. 19, n. 2, p.185-200, 2001

GALlEGO, A. R.; MARTÍNEZ, E. C.; MARTÍNEZ, A. R. L. Gestión de la Calidad. 1. ed. Cartagena: Universidad Politécnica de Cartagena, 2003. 354 p.

JURAN, J. M., Planejando para a qualidade. São Paulo: Pioneira, 1990. 394p.
MAPA - Ministerio de Agricultura, Pesca y Alimentación. Organizaciones Interprofesionales y Contratos Agrarios. Madri, 2001. Disponível em: http://www.mapya.es/ alimentacion/organizaciones/organizaciones.htm. Acesso em: 22 de abr. 2003

SANTOS, M. V. Situação da qualidade do leite e do queijo comercializados no Brasil. São Paulo, 2001. Disponível em: http://www.milkpoint.com.br. Acesso em: 18 de jun. 2004.

SCALCO, A. R. Diagnóstico, Análise e Proposições para a Gestão da Qualidade na Agroindústria de Laticínios do Estado de São Paulo. 1999. 150 f. Dissertação (Mestrado em Engenharia de Produção). Programa de Pós-Graduação em Engenharia de Produção, UFSCar, 1999.

Proposta de Modelo para Coordenação da Qualidade na Cadeia de Produção de Leite e Derivados. 2004. 215 f. Tese (Doutorado em Engenharia de Produção). Programa de Pós-Graduação em Engenharia de Produção, UFSCar, 2004.

SCHIEFER, G. Environmental control for process improvement and process efficiency in supply chain management - the case of meat chain. International Journal of Production Economics, v. 78, n. 2, p. 197-206, 2002.

TOLEDO, J. C.; SCALCO, A. R.; LIMA, L. S.; BORRÁS, M. A. A.; SIMÃO, S. B. Proposição de Modelo para Coordenação da Qualidade em Cadeias de Produção Agroalimentares. In: INTERNATIONAL CONFERENCE ON AGRI-FOOD CHAIN ECONOMICS AND MANAGEMENT, 4., 2003, Ribeirão Preto. Proceedings... Ribeirão Preto: Faculdade de Economia, Administração e Contabilidade, 2003. CD-ROM.

WILLIAMSON, O. E. The Economic Institutions of Capitalism. New York: The Free Press, 1985. 450 p.

ZIGGERS, G. W.; TRIENEKENS, J. Quality Assurance in Food and Agribusiness Supply Chains: developing successful partnerships. International Journal of Production Economics, v. 60-61, n. 3, p. 271-279, 1999.

ZYLBERSZTAJN, D. Estruturas de Governança e Coordenação do Agribusiness: uma aplicação da nova economia das instituições. 1995. 238p. Tese (Livre Docência em Administração) - Programa de Pós-Graduação em Engenharia de Produção.Universidade de São Paulo, São Paulo, 1995. 


\title{
COORDINATION OF QUALITY IN PRODUCTION CHAINS: STRUCTURE AND METHOD FOR AGRI-FOOD CHAINS
}

\begin{abstract}
Today's reality prevents companies in general from planning or acting alone, requiring that they engage in coordinated action with others in the same production chain. For this reason, production chain coordination is becoming a widespread practice to promote integrated management of companies that share the goal of adding value to the final product of the chain. There are many reasons for coordinated action in production chains, including improvement of product quality and reduction of losses and of production and transactions costs. This paper discusses the problem of quality in agri-food production chains. A model is proposed for quality coordination to aid in both product quality assurance and improved quality throughout the chain. The model is structured on the following elements: the agrifood production chain and its segments, product quality and quality management requirements of customers and of the institutional environment, the coordinating agent and the coordination information system. This system comprises information on product quality and quality management requirements, production chain quality performance indicators, the identification of problems, action plans and monitoring of improvements.
\end{abstract}

Keywords: quality coordination, agri-food production chain, quality coordination method. 